\title{
Nurse strategy in the prevention of acute cerebrovascular accident in young adult population
}

\begin{abstract}
Strokes in young users generate a high number of deaths, and a high rate of disability in this population, causing a demand for care and attention that influence both the affected person and their family. The health professional has to carry out a crucial task in the early identification of risk factors, as well as developing effective prevention measures to solve this problem. For this reason, the objective of this narrative review is to analyze the preventive measures carried out by nursing professionals in the care of young patients susceptible to having a stroke, due to the high increase in its incidence. The search for the articles was carried out in various scientific databases with the help of a search string, which combined the keywords and Boolean operators. Twenty-four studies were selected, which indicated that most preventive measures focus on factors such as hypertension, without taking into account its predictive factors, such as substance abuse. Using the ASCO etiologic classification helps establish a more accurate etiologic diagnosis. Nursing plays a fundamental role in maintaining secondary prevention measures, since 40 and $50 \%$ of patients abandon treatment after two or three years.
\end{abstract}

Keywords: ICTUS, primary prevention, risk factors, stroke
Volume 6 Issue 3 - 2021

\author{
Astasio Picado Álvaro \\ PhD Nursing and Physiotherapy Department, University of \\ Castilla-La Mancha, Spain
}

Correspondence: Álvaro Astasio Picado, PhD Nursing and Physiotherapy Department, University of Castilla-La Mancha, Federico García Lorca, 2I, Plasencia (10600-Cáceres), Spain, Email alvaro.astasio@gmail.com

Received: May 18, 202I | Published: June 02, 202 I

\section{Introduction}

According to the World Health Organization (WHO), Stroke is a focal neurological condition (or sometimes general) of sudden onset, lasting more than 24 hours (or leading to death) and whose apparent cause is of vascular origin. ${ }^{1}$ CVDs can be divided into two large groups according to their production mechanism. ${ }^{2}$ Ischemic stroke or cerebral ischemia, also called cerebral infarction, represents between $80-85 \%$ of all strokes, including transient ischemic accidents (TIA), originates from due to an occlusion of one of the arteries supplying the brain. ${ }^{2}$ According to the evolution in the first hours, two main types of ischemic cerebrovascular events are distinguished: transient ischemic attack (TIA), defined as the neurological deficit that recovers before the first $24 \mathrm{~h}$, and cerebral infarction. ${ }^{2,3}$

The ischemic stroke can be divided in turn into cardioembolic stroke, produced by an embolic heart disease such as fibrillation or atrial flutter, among others. Atherothrombotic stroke related to a stenosis greater than $50 \%$ of a large caliber extracranial or intracranial artery. ${ }^{2,3}$ Stroke due to small vessel (lacunar) involvement is infarction less than $1.5 \mathrm{~cm}$ in the area of a perforating artery. ${ }^{3}$

Hemorrhagic stroke represents $15-20 \%$ of all strokes, they are extravasations of blood within the brain as a consequence of the rupture of a vessel..$^{3,4}$ The most frequent etiology is arterial hypertension..$^{3-5}$

Although the incidence of stroke increases with age, between $3-10 \%$ of stroke cases occur in young people between 15 and 45 years of age. Therefore, this pathology occurs in around 6-20 cases per 100,000 inhabitants / year, being significantly higher in patients between 40 and 44 years of age. ${ }^{6,7}$

At 6 months after the stroke, $26.1 \%$ of the patients have died, $41.5 \%$ are independent and $32.4 \%$ are dependent. ${ }^{8}$

In relation to young adults who have suffered a stroke, the majority maintain an independence situation of $84 \%$. However, in many cases psychosocial problems are described, such as relationship problems, mood changes, etc. The risk of annual recurrence of stroke in this population is $1-3 \%{ }^{9}$
In young adults between the ages of 15 and 44, approximately $50 \%$ of strokes are ischemic, 20\% intracerebral hemorrhagic, and 30\% subarachnoid hemorrhagic. The incidence of strokes is higher in men than in women. $5,9,10$

Cerebral hemorrhage, especially subarachnoid hemorrhage, occurs in a greater proportion in young adults. On the other hand, ischemic stroke has a 33\% lower incidence than that given in older adults. $5,9,10,11$

Regarding the origin of ischemic strokes, $20 \%$ is attributed to cerebral embolisms of cardiac origin, and to unusual causes. ${ }^{9,10,12}$

For a better assessment of the etiology of stroke in the young patient, data that can guide specific etiologies should be assessed: ${ }^{9,10,13}$

a. Cardiovascular risk factors, such as hypercoagulability problems. ${ }^{14,15}$

b. Family history of coagulopathy. ${ }^{14,15,16}$

c. Problems in melatonin secretion. ${ }^{13}$

d. Family history (thrombophilia, vascular disease)..$^{14,15,16}$

e. Drug use. ${ }^{9,10,17,18}$

f. Study of risk factors. ${ }^{10,19}$

Strokes in young people are generally related to the presence of factors such as hypercoagulable states, genetic diseases or vascular malformations. ${ }^{9,10,14,15}$

In recent years, an increase in its incidence has been observed in relation to classic risk factors, due to the poor lifestyle of the population. ${ }^{5,9,10,13}$

High blood pressure (HT): There is a direct relationship between blood pressure and the risk of developing a stroke. ${ }^{13,15,24}$ The relationship is continuous, consistent and independent of other risk factors. Stroke risk increases significantly from systolic blood pressure below $115 \mathrm{mmHg}{ }^{20,24,25}$ It is one of the most important risk factors, since it occurs in almost $70 \%$ of patients with ictus. From 65 
years of age, the risk of stroke increases by one unit for every $10 \mathrm{~mm}$ $\mathrm{Hg}$ that increases systolic blood pressure. , $20,24,25^{2}$

Smoking: In smokers, the risk of stroke (ischemic and hemorrhagic) is $50 \%$ higher than in non-smokers. ${ }^{4,26}$ Smokers under 55 years of age have a relative risk of 2.9 of having a stroke, which it is higher when compared to smokers older than 55 years $(1.1 \%){ }^{4,26}$ Ischemic stroke is the one associated in greater proportion with this factor. However, the risk of hemorrhagic stroke is 2.5 times higher in smokers. ${ }^{4,26}$ On the other hand, ex-smokers continue to have a higher risk than those who do not smoke, despite cessation. Likewise, exposure to environmental tobacco smoke also increases the risk. ${ }^{4,20,26}$

Diabetes: The risk of having a stroke in these people may be due to the fact that diabetics have a greater predisposition to develop atherosclerosis, and a higher prevalence of hypertension, dyslipidemia and obesity. ${ }^{20,27}$

Obesity: Obesity is a risk factor for ischemic stroke in women and men. Abdominal obesity (increased waist-hip ratio) increases the risk of ischemic stroke by up to 3 times, especially in men..$^{19,20}$

Excessive alcohol consumption: Its high and continued intake can cause hypertension, coagulopathies and cardiac arrhythmias..$^{20}$ More than $60 \mathrm{~g}$ /day of alcohol doubles the risk of hemorrhagic stroke. ${ }^{4}$

Drug use: Recreational marijuana use is associated with a $17 \%$ increase in the risk of ischemic stroke. ${ }^{17,18}$

Diet: In overweight individuals, high sodium intake is associated with an approximately $89 \%$ increased risk of stroke mortality (as it partially alters blood pressure values). ${ }^{19,20}$

Dyslipidemia: It has been observed that there is a $25 \%$ increased risk of stroke with every $1-\mathrm{mmol} / \mathrm{L}(38.7 \mathrm{mg} / \mathrm{dL})$ increase in total cholesterol. This factor has a higher incidence of fatality in women. ${ }^{19,20}$

Sex: In general, stroke is more frequent in women older than 85 years. However, the incidence in the young population is, on the contrary. ${ }^{19,20}$

Heart disease: the presence of hypercoagulable states in patients younger than 55 years is related to $46 \%$ of the incidence of stroke in this population. ${ }^{4}$

On the other hand, the ignorance of the signs and symptoms of the pathology in general, added to the false belief that the pathology is only characteristic of the elderly population, increase the risk of suffering the disease. ${ }^{9}$

The main objective of this work is to analyze the preventive measures carried out by nursing professionals in the care of young patients susceptible to having a stroke, due to the high increase in its incidence.

\section{Material and methods}

The preparation of this work was carried out through a bibliographic search in scientific databases between the month of November 2019 and March 2020, in order to carry out a narrative review of the literature.

For the selection of the scientific articles on which this narrative review is based, the following criteria have been carried out:

\section{Inclusion criteria:}

i. Research articles in English, French and Spanish were selected.

ii. Articles focused on interventions aimed at stroke prevention, risk factors and stroke incidence in young adult patients between 18 and 55 years of age. iii. Articles that mentioned at least 4 terms in the search string.

iv. Articles published in the last 5 years, with dates between January 2, 2015 and July 22, 2019.

v. Exclusion criteria:

vi. No studies were selected that did not have English / Spanish / French as the language.

vii. Articles that were not focused on interventions aimed at prevention, risk factors and stroke incidence in young adult patients between 18 and 55 years.

viii. Articles that did not mention at least 4 terms in the search string.

ix. Articles whose publication year was prior to 2014 included.

The studies will be identified by means of computerized searches in bibliographic databases and in reference lists of articles. The selected sources of information were in the language of English, French and Spanish. The following databases were used: Pubmed (2014-2019), Scopus (2014-2019), Wos (2014-2019), Google Scholar (2014-2019). The first search was carried out on November 12, 2019 and ended on March 2, 2020. In addition to searching databases, the list of article references was verified8,9,12 and the information was also supplemented. obtained through the analysis of trial registers, protocols and institutional websites.

In November 2019, the electronic bibliographic databases of Pubmed, Scopus, Wos, Google Scholar were consulted to locate articles published from 2014 inclusive, until 2019. The language of the studies was limited to English / French / Spanish. Keywords such as "stroke", "primary prevention", "secondary prevention", "nursing care", "risk factors", "young adults" were used in the search strategy. Reference lists of included studies were checked to select the most complete ones.

First, a clearly defined question (PICOS) was asked:

P: ("Stroke" or "Brain injury") or "Ischemic stroke" or "Hemorrhagic stroke" or "Cerebral stroke" and "Young adults".

I: "nursing care" or ("nursing educations" or "behavioral nurse intervention" or "behavior") or "mixed intervention" or "pharmaceutical intervention".

C: "Patients that don’t receive intervention" or a "clearly justified comparision".

O: "Primary prevention" or "Secondary prevention" or "Risk factors" or "Quality of life" or "Incidence".

Secondly, in reference to the PICOS question, the search for articles was reinforced, through the creation of a chain, which was as follows:

("Ischemic Stroke" OR "Hemorrhagic Stroke" OR "Stroke") AND ("Nursing Care" OR "Nursing Educations" OR "Pharmacy Education") AND ("Primary Prevention" "Secondary Prevention" OR "Incidences" OR "Risk factors "OR" Quality of life "OR" Young Adults ").

To carry out the selection of these studies, a first bibliographic search was carried out, from which 2,851 articles were obtained. After applying the inclusion and exclusion criteria, a total of 1,139 articles were identified. Subsequently, after eliminating duplicate and irrelevant articles both by their abstract and by their title, 180 articles were selected. Of these 180 articles, 156 were excluded because they did not provide relevant information of interest, so the studies selected for this review were 24 articles. 


\section{Results}

Below is a Figure 1 that shows the search strategy used to select the articles:

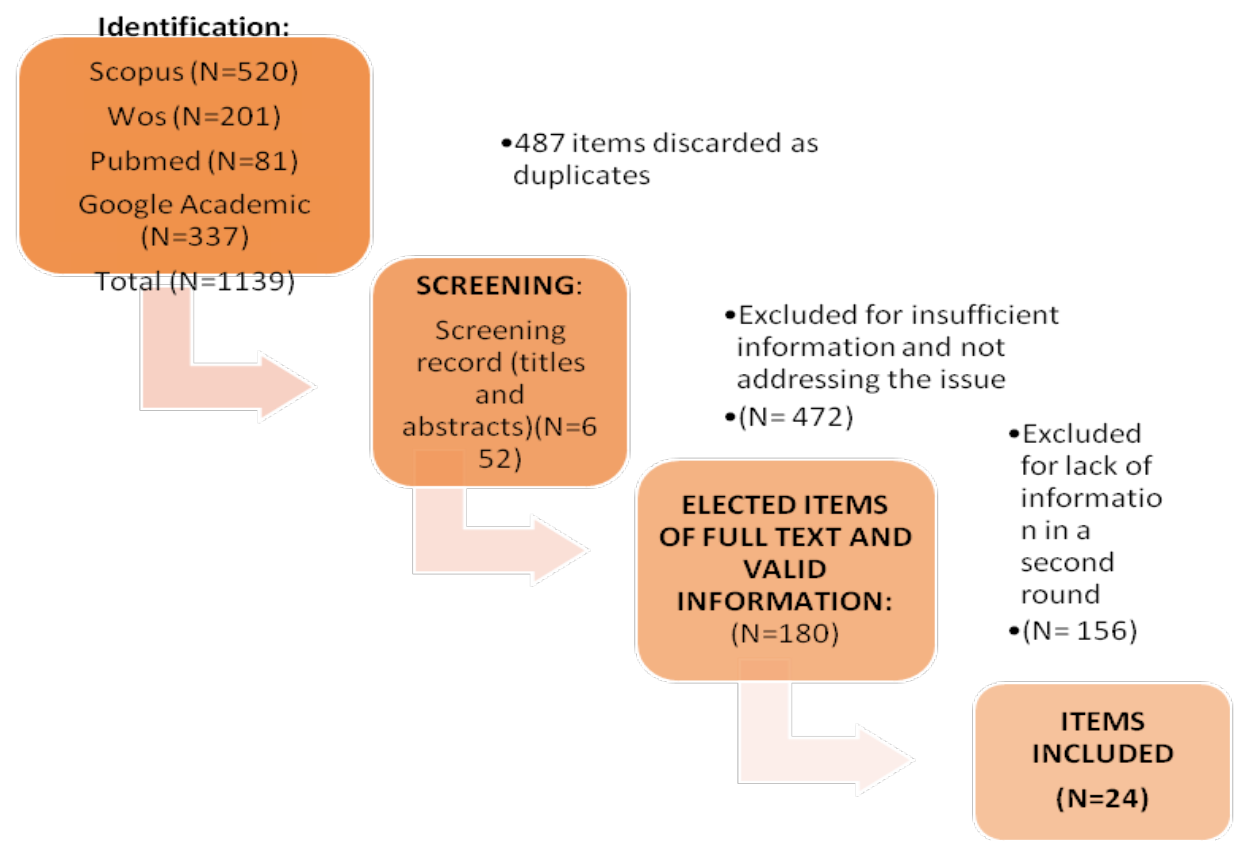

Figure I Diagrama de flujo de los estudios seleccionados.

\section{Discussion}

Strokes in young adults are considered infrequent, however, they reach 10 and $15 \%$ of all patients suffering from this pathology. Likewise, compared to stroke in older adults, stroke in young adults has a proportionally greater economic impact by leaving disabled patients before their most productive years. ${ }^{5,9,10,28}$

The mortality risk of young patients suffering a stroke is between $1.5-7.5 \%$, despite this, more than $75 \%$ of patients do not present significant sequelae after the first episode of the stroke. Within this percentage, less than $70 \%$ of patients return to work, and at least a quarter of them must adapt their condition to their work routine. . $^{5,9,10,22,29}$

The majority of young adults who survive a stroke maintain a situation of independence (around 84-94\%), however, in many cases psychosocial problems are described, such as mood changes, depression, divorce or unemployment. Post-stroke depression has an incidence of $38.7 \%$ among patients, this is due to the anxiety and stress caused by people not being able to carry out common activities independently physically. ${ }^{4,5,9,10,11.22}$

Modifiable risk factors for stroke, such as dyslipidemia, smoking, sedentary lifestyle, and hypertension, are highly prevalent in the young population. Unmodifiable risk factors such as diabetes, hypercoagulability problems, genetic states, or heart disease are also present. ${ }^{5,10,11,13-16,19,21,23,26,27,32}$

The incidence of these factors is higher in men younger than 45 years. This could be related to the protective role that estrogens play in women. Subsequently, this protective factor is lost with menopause, which explains the higher incidence of stroke in women> 85 years. . $^{9,10,16,23,24,25}$

The possible etiologies of stroke among young adults are several. Strokes of undetermined etiology are the most common types, representing $20-30 \%$ according to the TOAST criteria. On
To carry out the narrative review, 24 articles were used that studied the procedure of previous action of the infirmary against the Stroke in the young adult patient. 
Regarding smoking, studies indicate that there is a great relationship between tobacco and ischemic stroke and subarachnoid hemorrhage. Tobacco increases its harmful effect through its association with other factors, such as hypertension, diabetes mellitus, physical inactivity or the use of ACO. Therefore, smoking cessation programs must be widespread and effective. . $^{25,26,27}$

On the other hand, secondary prevention should be aimed at reducing the risk of recurrence of another stroke, by accurately identifying the etiology and controlling additional risk factors. The annual recurrence risk of a stroke in young patients is between $1-3 \% .^{5,9,10,21,23,32}$

This prevention focuses on the adequate control of vascular risk factors (HT, diabetes mellitus and heart disease) through the administration of antiplatelet or anticoagulant treatments, as well as surgical treatments. Furthermore, this prevention should focus on promoting moderate physical activity and a diet low in salt and fat, as well as weight control and abuse of toxic substances. In diabetic patients, stricter control of these factors should be carried out, since diabetes linked to other factors has a higher mortality and recurrence rate in young people and adults. , $^{5-11,13,14,26,27}$

\section{Conclusion}

Nursing from its role must begin to inform and instill in the young population healthy lifestyle habits that allow them to be less likely to suffer a stroke. Most preventive measures focus on factors such as HTA, without taking into account predictors of it, such as substance abuse. HT is the most important modifiable risk factor, considering the origin of half of the strokes. However, cocaine abuse and smoking, factors that are very present in the young population, actively influence the appearance of HT in this population. Therefore, nursing must address all risk factors, since, among them, they act in a chained way. The high percentage of strokes of unknown etiology among young people (20-30\%) is caused by the misuse of classification scales. As a consequence, preventive measures are established that do not address the control of all the risk factors of the individual, but focus on one in particular. Therefore, the use of the ASCO etiological classification helps to establish a more accurate etiological diagnosis. Nursing plays a fundamental role in maintaining secondary prevention measures, since 40 and $50 \%$ of patients abandon treatment after two or three years.

\section{Funding}

None.

\section{Acknowledgments}

None.

\section{Conflicts of interest}

The authors declare that there is no conflict of interest.

\section{References}

1. Organización Mundial de la Salud. Estrategia paso a paso de la OMS para la vigilancia de accidentes cerebrovasculares, 2005.

2. Ustrell-Roig X, Serena-Leal J. Ictus. Diagnóstico y tratamiento de las enfermedades cerebrovasculares. Rev Esp Cardiol. 2007;60(7):753-769.

3. Arauz A, Ruíz-Franco A. Enfermedad vascular cerebral. Revista de la Facultad de Medicina de la UNAM. 2012.

4. Troccoli M, Zambrano C, de Freitas J, Ictus Hemorrágico. Med Interna (Caracas). 2007.
5. Smajlović D. Strokes in young adults: epidemiology and prevention. Vasc Health Risk Manag. 2015;11:157-164.

6. Código Ictus. [Internet]. Federación Española de Ictus. 2017.

7. Mortalidad proporcional de residentes según sexos, causas de muerte e indicadores. [Internet] Instituto Canario de Estadística. 2019.

8. Bayo Poleo R, Benito Arroyo I, Casado Navarro I, et al. Plan de atención al ictus en Extremadura. Servicio Extremeño de Salud. 2010;5-11.

9. Parejo J.A, Salazar Gómez, L. Ictus en paciente joven. Med Interna. 2016;3 (1):9-26.

10. González-Gómez FJ, Pérez-Torre P, De Felipe A, et al. Ictus en adultos jóvenes: incidencia, factores de riesgo, tratamiento y pronóstico. Revista Clínica Española. 2016;216(7):345-351.

11. Van Alebeek ME, Arntz RM, Ekker MS, et al. Risk factors and mechanisms of stroke in young adults: The FUTURE study. J Cereb Blood Flow Metab. 2018;38(9):1631-1641.

12. Fan H, Hao X, Yang S, et al. Study on the incidence and risk factor of silent cerebrovascular disease in young adults with first-ever stroke. Medicine. 2018;97(48).

13. Onaolapo AY, Onaolapo OJ, Nathaniel TI. Cerebrovascular disease in the young adult: examining melatonin's possible multiple roles. $J$ Exp Neurosci [Internet]. 2019.

14. Martínez-Martínez M, Cazorla-García R, Rodríguez de Antonio LA, et al. Estados de hipercoagulabilidad e ictus isquémico en pacientes jóvenes. Neurología. 2015;25(6):343-348.

15. Zacharias Mandalenakis, MD, Annika Rosengren, MD, Georgios Lappas, MSc ischemic stroke in children and young adults with congenital heart disease. Journal of the American Heart Association. 2016:5(2).

16. Siegerink B, Maino A, Algra A, Rosendaal FR. Hypercoagulability and the risk of myocardial infarction and ischemic stroke in young women. Journal of Thrombosis and Haemostasis. 2015;13(9):1568-1575.

17. Gómez Ochoa SA. Ictus y consumo de cannabis en pacientes sin factores de riesgo cardiovascular: revisión sistemática de casos clínicos. Neurología. 2017.

18. Volpon LC, Sousa CLM de M, Moreira SKK, et al. Multiple cerebral infarcts in a young patient associated with marijuana use. J Addict Med. 2017;11(5):405-407.

19. Mesa BY, Hernández RTE, Parada BY. Factores determinantes de la calidad de vida en pacientes sobrevivientes a un ictus. Revista Habanera de Ciencias Médicas. 2017;16(5):735-750.

20. Grysiewicz RA, Thomas K, Pandey DK. Epidemiology of ischemic and hemorrhagic stroke: incidence, prevalence, mortality, and risk factors. Neurol Clin. 2008;26(4):871-895.

21. Janssen AWM, de Leeuw FE, Janssen MCH. Risk factors for ischemic stroke and transient ischemic attack in patients under age 50. J Thromb Thrombolysis. 2016;31(1):85-91.

22. Allaoui A, Echchilali K, Moudatir M, et al. Etiologies des accidents vasculaires cérébraux ischémiques chez les jeunes: apport de l'interniste. Pan Afr Med J [Internet]. 2018;30.

23. Schürks M, Rist PM, Bigal ME, Buring JE. La migraña con aura se asocia a un aumento del riesgo de ictus isquémico. FMC - Formación Médica Continuada en Atención Primaria. 2015;17(5):369.

24. Arboix A, Massons J, García-Eroles L, et al. Stroke in young adults: incidence and clinical picture in 280 patients according to their aetiological subtype. Med Clin (Barc). 2016;146(5):207-211.

25. Cabral NL, Freire AT, Conforto AB, et al. Increase of stroke incidence in young adults in a middle-income country: A 10-Year population-based study. Stroke. 2017;48(11):2925-2930. 
26. Shah RS, Cole JW. Smoking and stroke: the more you smoke the more you stroke. Expert Rev Cardiovasc Ther. 2017;8(7):917-32.

27. Tuttolomondo A, Pinto A, Salemi G, et al. Diabetic and non-diabetic subjects with ischemic stroke: differences, subtype distribution and outcome. Nutr Metab Cardiovasc Dis. 2015;18(2):152-157.

28. Tejada Meza H, Artal Roy J, Pérez Lázaro C, et al. Epidemiología y características del ictus isquémico en el adulto joven en Aragón. Neurología. 2019

29. Camoes-Barbosa A, Sequeira-Medeiros L, Duarte N, et al. Afasia y depresión post-ictus: una relación predictiva. Rehabilitación (Madr). 2014;46(1):36-40.

30. Clua-Espuny JL, Piñol-Moreso JL, Panisello-Tafalla A, et al. Estudio ebrictus. resultados funcionales, supervivencia y años potenciales de vida perdidos después del primer episodio de ictus. Atención Primaria. 2014;44(4):223-231.
31. Tejada Meza H, Artal Roy J, Pérez Lázaro C, et al. Epidemiología y características del ictus isquémico en el adulto joven en Aragón. Neurología. 2019

32. Visnja Supanc, MD. The role of classic risk factors and prothrombotic factor gene mutations in ischemic stroke risk development in young and middle-aged individuals. - Abstract - Europe PMC [Internet]. 2014 Mar;23(3):e171-176.

33. Sobrino García P, García Pastor A, García Arratibel A, et al. Clasificación etiológica del ictus isquémico: comparación entre la nueva clasificación A-S-C-O y la clasificación del Grupo de Estudio de Enfermedades Cerebrovasculares de la Sociedad Española de Neurología. Neurologia. 2014;28(7):417-424.

34. Cárcamo-Mejía S, Pavón-Núñez D, M Diaz C, et al, Caracterización del accidente cerebrovascular adultos jóvenes atendidos en el Hospital Escuela Universitario, Tegucigalpa, Honduras durante los años 2013 2015. Revista Hispanoamericana de Ciencias de la Salud. 2016;(2):2 